\title{
Nuclear gene phylogeny of narrow-mouthed toads (Family: Microhylidae) and a discussion of competing hypotheses concerning their biogeographical origins
}

\author{
Arie van der Meijden ${ }^{\mathrm{a}, \mathrm{e}}$, Miguel Vences ${ }^{\mathrm{b}}$, Simone Hoegg ${ }^{\mathrm{a}}$, Renaud Boistel ${ }^{\mathrm{c}}$, \\ Alan Channing ${ }^{\mathrm{d}}$, Axel Meyer ${ }^{\mathrm{a}, *}$ \\ ${ }^{a}$ Lehrstuhl für Zoologie und Evolutionsbiologie, Department of Biology, University of Konstanz, P.O. Box M618, 78457 Konstanz, Germany \\ ${ }^{\mathrm{b}}$ Division of Evolutionary Biology, Zoological Institute, Technical University Braunschweig, Spielmannstr. 8, 38106 Braunschweig, Germany \\ ${ }^{\mathrm{c}}$ Equipe Communications Acoustiques, NAMC, CNRS UMR 8620, IBAIC Bat 446 Université Paris Sud, F-91405 Orsay, France \\ ${ }^{\mathrm{d}}$ Department of Biodiversity and Conservation Biology, University of the Western Cape, Private Bag X17, Bellville 7535, South Africa \\ ${ }^{\mathrm{e}}$ Institute of Biodiversity and Ecosystem Dynamics, University of Amsterdam, P.O. Box 94062, 1090 GB Amsterdam, The Netherlands
}

\begin{abstract}
The family Microhylidae has a large circumtropic distribution and contains about 400 species in a highly subdivided taxonomy. Relationships among its constituent taxa remained controversial due to homoplasy in morphological characters, resulting in conflicting phylogenetic hypotheses. A phylogeny based on four nuclear genes (rag-1, rag-2, tyrosinase, BDNF) and one mitochondrial gene (COI) of representatives of all currently recognized subfamilies uncovers a basal polytomy between several subfamilial clades. A sister group relationship between the cophylines and scaphiophrynines is resolved with moderate support, which unites these endemic Malagasy taxa for the first time. The American members of the subfamily Microhylinae are resolved to form a clade entirely separate from the Asian members of that subfamily. Otophryne is excluded from the subfamily Microhylinae, and resolved as a basal taxon. The placement of the Asian dyscophine Calluella nested within the Asian Microhyline clade rather than with the genus Dyscophus is corroborated by our data. Bayesian estimates of the divergence time of extant Microhylidae (47-90 Mya) and among the subclades within the family are discussed in frameworks of alternative possible biogeographic scenarios.
\end{abstract}

Keywords: Amphibia; Microhylidae; Mirohylinae; Dyscophinae; Asterophryinae; Cophylinae; Scaphiophryninae; Hoplophryninae; Gastrophryninae; Phrynomerinae; Molecular phylogeny

\section{Introduction}

Amphibians have long been regarded as model organisms for the study of biogeography due to their alleged inability to disperse across salt water. Several recent molecular studies have shed new light on the biogeography of anurans (Bossuyt and Milinkovitch, 2001; Biju and Bossuyt, 2003; San Mauro et al., 2005; Van der Meijden et al.,

\footnotetext{
* Corresponding author. Fax: +497531883018.

E-mail address: Axel.Meyer@uni-konstanz.de (A. Meyer).
}

2005). Although plate tectonics and terrestrial dispersal are generally assumed to be the dominant forces shaping largescale patterns of anuran biogeography, transoceanic dispersal has been shown to have occurred in several instances (Hedges et al., 1992; Vences et al., 2003b; Measey et al., 2007).

The frogs of the family Microhylidae occur in the Americas, sub-Saharan Africa, Madagascar, India, and most of Southeast Asia to New Guinea and northernmost Australia, while the highest numbers of species are found in Southeast Asia and Madagascar. This wide distribution makes the Microhylidae a model case for biogeographical 
inference. A typical Gondwanan distribution suggests that their current distribution is primarily due to large-scale vicariance events. Savage (1973) proposed that the early microhylids were present on Gondwana, and their current distribution on Gondwanan continents is due to the breakup of the supercontinent. India and Australia subsequently were the origin of the Southeast Asian microhylids through dispersal from there, while some of the South American taxa spread northward to North America. More recently, Feller and Hedges (1998) proposed an "Out of Africa" pattern of dispersal for this family. They suggested dispersal from Africa to Asia and to North and South America as well as to Madagascar.

Although they are generally characterized as stout bodied mostly fossorial ant- and termite-specialists, microhylids are actually rather diverse in their biology. Most are fossorial or terrestrial, but arboreal forms also exist. The Asterophryinae and Genyophryninae of Southeast Asia and Australia undergo direct development, whereas all cophylines have endotrophic, non-free living tadpoles (McDiarmid and Altig, 1999). Both the subfamilies Microhylinae and Hoplophryninae contain species that have endotrophic larvae and species that have feeding and free swimming larvae. Although free exotrophic larvae are considered to be plesiomorphic for ranoid frogs, only about a third of the microhylid species retained this characteristic.

Approximately one in every five frog genera belongs to the Microhylidae. While this family encompasses $20 \%$ (64) of all frog genera, it includes only 8\% (approximately 400) of the world's frog species (Amphibiaweb, 2006), a low average number of species per genus. There are on average only 5.2 species per genus, while families with a wide distribution like the Bufonidae and the Hyperoliidae have 13.8 and 13.4 species per genus, respectively. Of the 64 genera, 22 are monotypic.

Microhylids display a high level of morphological diversity. This high variability in morphological characters, especially of the cranium and pectoral girdle (Parker, 1934; Blommers-Schlosser, 1993), and high levels of homoplasy due to loss of pectoral girdle elements in members of all subfamilies has complicated the use of these characters for microhylid taxonomy (Zweifel, 1986). The high variability of these elements might be a by-product of miniaturization (as in Hanken and Wake, 1993), independently recurring in several clades. Wild (1995) attributed the high variability in their osteological characters to the effects of miniaturization and the inferred repeated evolution of fossoriality. This high diversity and frequent homoplasy of morphological characters (Zweifel, 1986; Blommers-Schlosser, 1993; Loader et al., 2004) is probably the cause of the severe taxonomic subdivision of the Microhylidae in eight subfamilies and the high genus to species ratio. Its biological and morphological diversity organized in a highly subdivided taxonomy, in combination with their puzzling distribution, has gained the Microhylidae a reputation of being systematically difficult (Duellman, 1979; Ford and Cannatella, 1993).
In this work, we will use the terms Microhylidae and microhylids sensu Frost et al. (2006) to refer to the monophyletic microhylid group excluding the African subfamily Brevicipitinae, which has been shown to be closer related to hyperoliids and arthroleptids than to the non-brevicipitine microhylids in previous studies (Darst and Cannatella, 2004; Loader et al., 2004; Van der Meijden et al., 2004; Frost et al., 2006).

Recent molecular phylogenetic studies (Sumida et al., 2000; Hoskin, 2004; Loader et al., 2004; Van der Meijden et al., 2004; Andreone et al., 2005) focussed on a comparatively small part of the circumtropic distribution of the Microhylidae, or concentrated on one or more subtaxa. Frost et al. (2006) presented the first broad phylogenetic hypothesis for the Microhylidae, but like Van Bocxlaer et al. (2006), omitted some taxa of controversial placement, like Otophryne and Paradoxophyla. In this paper, we present an inclusive molecular phylogeny of the Microhylidae, sampling all eight subfamilies. We also included a range of ranoid and arthroleptoid frogs as outgroups, to further establish the position of the Microhylidae relative to these taxa. We discuss the systematic and biogeographic implications of our findings.

\section{Materials and methods}

\subsection{Higher-level classification}

Numerous classificatory schemes for anurans have been proposed but, although tending to incorporate novel phylogenetic information as it became available, they disagreed in the ranks assigned to family-group taxa. Van der Meijden et al. (2005) distinguished three monophyletic lineages within a superfamily Ranoidea: Arthroleptoidae, Microhyloidae and Ranoidae. These lineages were named "epifamilies" following Dubois (1992) but in a subsequent paper, Dubois (2005) suggested a different epifamily definition in which this rank applies to units above the superfamilial level. We disagree with the classification proposed by Dubois (2005) which sank a number of well-established and largely well-defined families such as Arthroleptidae, Astylosternidae, Hemisotidae, Hyperoliidae as subfamilies into a new family Brevicipitidae, but rather agree with Frost et al. (2006) to maintain these families. Likewise we consider the new taxonomic assignments of ranid subfamilies by Scott (2005) as premature and probably in many cases not reflecting the correct phylogeny. The high rates of discovery of new species as well as active work on the phylogenetic relationships of amphibians (Köhler et al., 2005) also require modifications of their classification and, in our opinion, warrant the recognition of additional new families rather than a reduction of the number of family group taxa. For the purpose of this paper we follow the scheme used in Van der Meijden et al. (2005) without referring to "epifamilial" taxa but rather will describe the clades, and accept the Brevicipitidae as a separate family (including the genera Balebreviceps, Breviceps, Callulina, Probreviceps, Spelaeophryne) following Frost et al. (2006). 


\subsection{Selection of taxa}

Our sampling consisted of 34 microhylid species representing all currently recognized subfamilies. We included several outgroup taxa to resolve the relationships of the Microhylidae to its closest relatives. To represent the two major clades in the Ranoidea besides the Microhylidae we included (1) the arthroleptids Arthroleptis and Trichobatrachus, the brevicipitids Breviceps and Callulina, the hemisotid Hemisus, and the hyperoliids Hyperolius and Leptopelis, and (2) the ranid Rana and two mantellids of the genus Mantidactylus. The hylids Litoria and Agalychnis, and the pipids Xenopus and Pipa as well as two species of Alytes were included to further represent major groups in the anuran phylogeny. We further included the salamander Lyciasalamandra, a bird and a mammal to account for the synapsid-diapsid split for molecular clock calibration, and the lungfish Protopterus as outgroup.

\subsection{Sequencing and alignment}

DNA was extracted from toe clips fixed in $99 \%$ ethanol. Tissue samples were digested using proteinase $\mathrm{K}$ (final concentration $1 \mathrm{mg} / \mathrm{mL}$ ), homogenized and subsequently purified following a high-salt extraction protocol (Bruford et al., 1992). Primers for rag-1 and rag-2 were from Hoegg et al. (2004). Primers for tyrosinase from Bossuyt and Milinkovitch (2000) were used as in Vences et al. (2003a). Primers were designed for an amplification of a $700 \mathrm{bp}$ fragment of BDNF (Brain-derived neurotrophic factor) (BDNF.Amp.F1 ACCATCCTTTTCCTTACTATGG, BDNF.Amp.R1 CTA TCT TCC CCT TTT AAT GGT C). CO1 primers were from Hebert et al. $(2003,2004)$ and used as in Vences et al. (2005). PCR was performed in $25 \mu \mathrm{reac}-$ tions containing 0.5-1.0 units of REDTaq DNA Polymerase (Sigma, Taufkirchen, Germany), $50 \mathrm{ng}$ genomic DNA, $10 \mathrm{pmol}$ of each primer, $15 \mathrm{nmol}$ of each dNTP, $50 \mathrm{nmol}$ additional $\mathrm{MgCl}_{2}$ and the REDTaq PCR reaction buffer (in final reaction solution: $10 \mathrm{mM}$ Tris- $\mathrm{HCl}, \mathrm{pH} 8.3,50 \mathrm{mM}$ $\mathrm{KCl}, 1.1 \mathrm{mM} \mathrm{MgCl}_{2}$ and $0.01 \%$ gelatin). For rag-1 and rag2 cycle conditions were adapted from a long range PCR protocol (Barnes, 1994), with an initial denaturation step at $94^{\circ} \mathrm{C}$ for $5 \mathrm{~min}$, followed by ten cycles with $94^{\circ} \mathrm{C}$ for $30 \mathrm{~s}$, annealing temperatures increasing by $0.5^{\circ} \mathrm{C}$ per cycle from 52 to $57^{\circ} \mathrm{C}$ and extending for $3 \mathrm{~min}$ at $68^{\circ} \mathrm{C}$. Additionally, 20 cycles were performed with $94^{\circ} \mathrm{C}$ for $10 \mathrm{~s}, 57^{\circ} \mathrm{C}$ for $40 \mathrm{~s}$ and $68^{\circ} \mathrm{C}$ for $3 \mathrm{~min}$. The final extension was done at $68^{\circ} \mathrm{C}$ for $5 \mathrm{~min}$. PCR products were purified via spin columns (Qiagen). Sequencing was performed directly using the corresponding PCR primers (forward and reverse). DNA sequences of both strands were obtained using the BigDye Terminator cycle-sequencing ready reaction kit (Applied Biosystems Inc.) on an ABI 3100 capillary sequencer using the manufacturer's instructions. New sequences were combined with existing sequences taken from GenBank in the final dataset. New sequences were deposited in GenBank (for Accession numbers see Table 1).
Chromatograms were checked by eye using Sequencher (Gene Codes Corp., Ann Arbor, USA) or Chromas v.1.45 (Technelysium Pty Ltd., Tewantin, Australia) and the sequences were subsequently aligned using the Mega3 alignment editor (Kumar et al., 2004). The sequences were aligned using ClustalW (Thompson et al., 1994) with a gap opening penalty of 15 and a gap extension penalty of 6.66. The alignment was checked by eye based on the amino acid sequence. In spite of attempts to design specific primers, for a few taxa, not all gene sequences could be obtained (Table 1). Except a few outgroup taxa and two species where complete data sets were available from other, clearly congeneric species (Stumpffia and Microhyla), this mainly regards Hoplophryne (only partial rag-1 sequence, COI missing) and Hamptophryne (tyrosinase and COI missing). Missing genes were coded as "missing" (?) in the concatenated dataset. In Bayesian Inference (BI) and Maximum Parsimony (MP) analyses of large multigene data sets of hylid frogs, no relationship has been found between completeness of the sequence data of a taxon, and the support values the taxon receives (Wiens et al., 2005), suggesting that the limited amount of missing data in our concatenated alignment is unlikely to distort the phylogenetic results. Furthermore, the placement of taxa with missing data in our analysis was congruent between the single gene analyses in which the taxon was represented by a complete sequence, and the combined dataset, suggesting that omission of one or more genes from the combined set did not influence the placement of particular taxa.

\subsection{Data analysis}

A homogeneity partition test (Farris et al., 1994) as implemented in PAUP* (Swofford, 2002) rejected homogeneity of the different markers $(P=0.01)$. Besides an analysis of the combined data set we therefore also performed separate analyses of each of the various genes. Transitions and transversions were plotted against F84 distances (Felsenstein, 1984) for the separate gene lignments. Of the nuclear genes, only tyrosinase showed slight deviance from a linear relationship between the number of transitions and the genetic distance for the most distantly related outgroup taxa. This gene was therefore excluded from the divergence time estimates.

Phylogeny reconstruction based on the separate and combined datasets was performed using Maximum Likelihood (ML) and Bayesian Inference (BI) methods. The best fitting models of sequence evolution were determined by the AIC criterion in Modeltest 3.7 (Posada and Crandall, 1998). ML tree searches were performed using PhyML, version 2.4.4 (Guindon and Gascuel, 2003). Bootstrap branch support values were calculated with 500 replicates. The Bayesian analyses of the combined and separate datasets were conducted with MrBayes 3.1.1 (Huelsenbeck and Ronquist, 2001), using models estimated with Modeltest under the AIC criterion, with 250,000 generations, 
Voucher specimens and accession numbers of taxa studied

\begin{tabular}{|c|c|c|c|c|c|c|c|}
\hline \multirow[t]{2}{*}{ Species } & \multirow[t]{2}{*}{ Family } & \multirow[t]{2}{*}{ Locality, Voucher } & \multicolumn{5}{|c|}{ Accession number } \\
\hline & & & rag-1 & rag-2 & tyrosinase & $B D N F$ & $\mathrm{CO1}$ \\
\hline Anodonthyla boulengerii & Microhylidae & Foulpointe, Madagascar, ZSM 264/2002 & EF396072 & EF396110 & EF395959 & EF395994 & EF396036 \\
\hline Anodonthyla montana & Microhylidae & Andringitra, Madagascar, UADBA uncatalogued (fieldnumber MV 2001.530) & EF396071 & EF396111 & EF395960 & EF395995 & EF396037 \\
\hline Asterophrys turpicola & Microhylidae & Steve Richards, SJR5795 & EF396074 & EF396113 & EF395961 & EF395996 & EF396038 \\
\hline Calluella guttulata & Microhylidae & Ubon province, Thailand, ZSM434/2002 & EF396078 & EF396115 & EF395964 & EF395999 & EF396041 \\
\hline Chiasmocleis hudsoni & Microhylidae & French Guyana, MNHN uncatalogued & EF396079 & EF396118 & EF395967 & EF396001 & EF396043 \\
\hline Chiasmocleis shudikarensis & Microhylidae & French Guyana, personal collection Christian Marti, 119MC & EF396080 & EF396117 & EF395966 & EF396002 & EF396044 \\
\hline Cophixalus sp. & Microhylidae & Steve Richards, SJR3271 & EF396081 & EF396119 & EF395968 & EF396003 & EF396045 \\
\hline Dermatonotus muelleri & Microhylidae & Paraguay, voucher not preserved & EF396082 & EF396120 & EF395969 & EF396004 & EF396046 \\
\hline Dyscophus antongilii & Microhylidae & Maroantsetra, Madagascar (no voucher) & EF396084 & EF396122 & EF395970 & EF396005 & EF396047 \\
\hline Dyscophus insularis & Microhylidae & Antsirasira, Madagascar, UADBA uncatalogued (fieldnumber MV 2001.38) & EF396083 & EF396121 & EF395971 & EF396006 & EF396048 \\
\hline Elachistocleis ovalis & Microhylidae & French Guyana, personal collection Christian Marti, 146MC & EF396085 & EF396123 & EF395972 & EF396007 & EF396049 \\
\hline Gastrophryne carolinensis & Microhylidae & Pet trade (no voucher) & EF396086 & EF396124 & EF395973 & EF396008 & EF396050 \\
\hline Glyphoglossus molossus & Microhylidae & Sagaing, Myanmar, CAS 210056 & EF396087 & EF396125 & EF395974 & EF396009 & EF396051 \\
\hline Hamptophryne boliviana & Microhylidae & French Guyana, personal collection Michel Blanc, 42BM & EF396088 & EF396126 & Missing & EF396010 & ${ }^{\dagger}$ Missing \\
\hline Hoplophryne rogersi & Microhylidae & Bamba Ridge Forest Reserve, Tanzania & Missing & EF396128 & EF395976 & EF396012 & ${ }^{\dagger}$ Missing \\
\hline Hypopachus variolosus & Microhylidae & Nayarit, Mexico, MVZ 144018 & EF396090 & EF396129 & EF395977 & EF396014 & EF396052 \\
\hline Kaloula pulchra & Microhylidae & Pet trade (no voucher) & EF396091 & EF396130 & EF395978 & EF396015 & EF396053 \\
\hline Microhyla butleri & Microhylidae & Vinh Phu Province, Vietnam, MVZ 223728 & EF396094 & EF396132 & Missing & EF396019 & EF396054 \\
\hline Microhyla heymonsi & Microhylidae & Hainan province, China, MVZ 236751 & EF396095 & EF396133 & EF395979 & EF396020 & EF396055 \\
\hline Microhyla pulchra & Microhylidae & Vinh Phu Province, Vietnam, MVZ 223797 & EF396093 & EF396134 & EF395980 & EF396021 & EF396056 \\
\hline Micryletta inornata & Microhylidae & Pai near Chiang Mai, Thailand (voucher not preserved) & EF396096 & EF396135 & EF395981 & EF396022 & EF396057 \\
\hline Otophryne pyburni & Microhylidae & French Guyana, personal collection Christian Marti, $1116 \mathrm{MC}$ & EF396097 & EF396136 & EF395982 & EF396023 & EF396058 \\
\hline Paradoxophyla palmata & Microhylidae & Ranomafana, Madagascar, ZSM 792/2003 & EF396098 & EF396137 & EF395983 & EF396024 & EF396059 \\
\hline Phrynomantis annectens & Microhylidae & Ongongo, Namibia, ZFMK 66771 & EF396099 & EF396139 & EF395985 & EF396025 & EF396060 \\
\hline Phrynomantis bifasciatus & Microhylidae & Coast province, Kenya, MVZ 234047 & EF396100 & EF396138 & EF395984 & EF396026 & EF396061 \\
\hline Platypelis grandis & Microhylidae & Mantadia, Madagascar, ZSM 163/2002 & EF396101 & EF396140 & EF395986 & EF396027 & EF396062 \\
\hline Plethodontohyla alluaudi & Microhylidae & Andasibe, Madagascar, ZSM 3/2002 & EF396102 & EF396141 & EF395988 & EF396028 & EF396063 \\
\hline Plethodontohyla brevipes & Microhylidae & Ranomafana, Madagascar, ZSM 649/2003 & EF396103 & EF396142 & EF395987 & EF396029 & EF396064 \\
\hline Ramanella cf. obscura & Microhylidae & Kandy, Sri Lanka, MNHN 2000.628 & EF396104 & EF396143 & EF395989 & EF396030 & EF396065 \\
\hline Rhombophryne testudo & Microhylidae & Nosy Be, Madagascar, ZSM 475/2000 & EF396105 & EF396144 & EF395990 & EF396031 & EF396066 \\
\hline Scaphiophryne calcarata & Microhylidae & Madagascar, ZSM 115/2002 & EF396106 & EF396145 & EF395991 & EF396032 & EF396067 \\
\hline Stumpffia psologlossa & Microhylidae & Nosy Be, Madagascar (tissue 2001f42) & EF396107 & Missing & EF395992 & EF396033 & EF396068 \\
\hline Stumpffia pygmaea & Microhylidae & Nosy Be, Madagascar (tissue 2001f21) & EF396108 & EF396146 & EF395993 & EF396034 & EF396069 \\
\hline Callulina kreffti & Brevicipitidae & Tanga region, Tanzania, MVZ 234046 & EF396077 & EF396116 & EF395965 & EF396000 & EF396042 \\
\hline Breviceps fuscus & Brevicipitidae & Big Tree, South Africa, ZFMK 66716 & EF396075 & DQ019520 & EF395962 & EF395997 & EF396039 \\
\hline Breviceps mossambicus & Brevicipitidae & Kwambonambi, South Africa, ZFMK 68849 & EF396076 & EF396114 & EF395963 & EF395998 & EF396040 \\
\hline Hemisus marmoratus & Hemisotidae & Coast province, Kenya, MVZ 233793 & AY364216 & EF396127 & EF395975 & EF396011 & EF396070 \\
\hline Hyperolius viridiflavus & Hyperoliidae & Barberton, South Africa, ZFMK 66726 & AY323769 & AY323789 & AF249161 & EF396013 & Missing \\
\hline Arthroleptis variabilis & Arthroleptidae & Cameroon, ZFMK 68794 & EF396073 & EF396112 & AY341756 & Missing & Missing \\
\hline Trichobatrachus robustus & Arthroleptidae & Nkongsamba, Cameroon, ZFMK 66453 & EF396109 & EF396147 & AY844192 & EF396035 & Missing \\
\hline Leptopelis natalensis & Hyperoliidae & Mtunzini, South Africa, ZFMK 68785 & EF396092 & EF396131 & AY341755 & EF396016 & Missing \\
\hline Mantidactylus wittei & Mantellidae & Madagascar, ZSM 405/2000 & AY323774 & AY323795 & AY341751 & EF396018 & Missing \\
\hline Mantidactylus sp. "Comoros" & Mantellidae & Mayotte, ZSM 652/2000 & AY323775 & AY323794 & AY341750 & EF396017 & Missing \\
\hline Rana (temporaria) & Ranidae & Voucher not collected & AY323776 & AY323803 & AF249182 & EF407507 & Missing \\
\hline Agalychnis callidryas & Hylidae & Pet trade (no voucher) & AY323765 & AY323780 & AY844153 & EF407508 & Missing \\
\hline Litoria caerulea & Hylidae & Pet trade (no voucher) & AY323767 & AY323793 & AY844131 & EF407509 & Missing \\
\hline
\end{tabular}




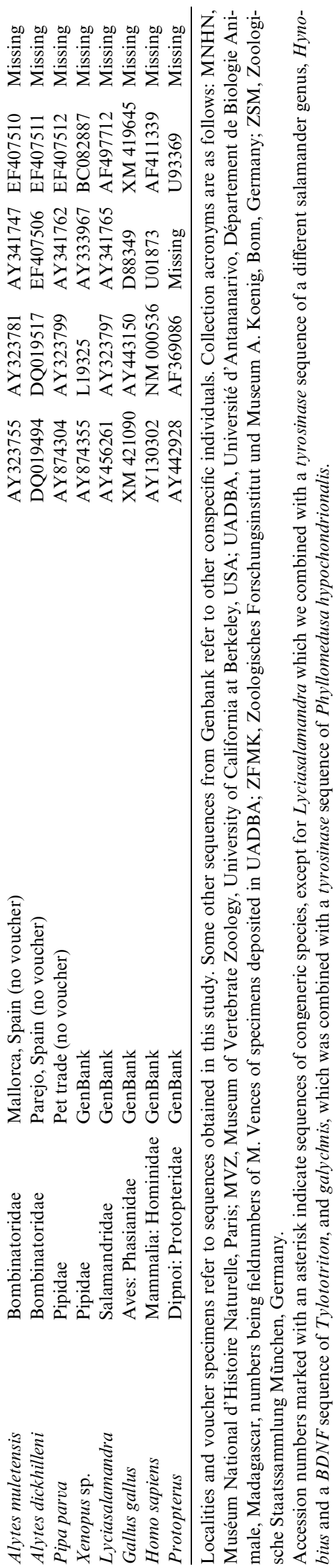

sampling trees every 10th generation (and calculating a consensus tree after omitting the first 3000 trees).

In addition to analyzing the dataset produced for this study, we analyzed the molecular data of Frost et al. (2006) for the Microhylidae and Brevicipitidae, using sequences of Rana and Litoria as outgroups. This dataset consisted of nuclear DNA sequences of histone $H 3$, rhodopsin, seven in absentia (SIA), tyrosinase, the $28 S$ ribosomal subunit and a section of mitochondrial DNA spanning $12 S$, The Val tRNA and $16 S$ sequences. Sequences for 34 species, including five outgroup species, were downloaded from GenBank and aligned using ClustalW (Thompson et al., 1994) with a gap opening penalty of 15 and a gap extension penalty of 6.66 . Hypervariable and gapped regions of the rRNA sequences were removed from the alignment. The amphibian origin of all downloaded sequences was confirmed by blasting them against the GenBank database using the NetBlast program, version 2.2.15 for win32 (NCBI). The best fitting models of sequence evolution were determined by the AIC criterion in Modeltest 3.7 (Posada and Crandall, 1998). ML and MP phylogenetic reconstructions were performed based on the combined alignment of 4045 basepairs using PhyML version 2.4.4 (Guindon and Gascuel, 2003) and Paup* (Swofford, 2002), respectively.

\subsection{Divergence time estimation}

Bayesian divergence time estimates were conducted using the software packages PAML (Yang, 1997) and Multidivtime (Thorne and Kishino, 2002) using a dataset consisting of only the nuclear genes rag-1, rag-2, and BDNF (2919bp). The following calibration points were used: (1) minimum age of the frog-salamander split at $230 \mathrm{Mya}$ (fossil record of frog ancestor Triadobatrachus; (Sanchiz, 1998)); (2) minimum age of the split between Agalychnis and Litoria at 42 Mya (last connection between Australia and South America; (Seddon et al., 1998)); (3) maximum age of the split between Mantidactylus wittei and Mantidactylus sp. from the Comoro islands at $15 \mathrm{Mya}$ (volcanic origin of the oldest Comoro island Mayotte; (Vences et al., 2003b)); (4) minimum age of the Alytes muletensis-Alytes dickhilleni split at $5 \mathrm{Mya}$ (Mediterranean salinity crisis: Fromhage et al., 2004); (5) age interval of the split between diapsids and synapsids at 338-288 Mya (Graur and Martin, 2004); (6) a minimum age of $338 \mathrm{Mya}$ for the divergence between Lissamphibia and Amniota based on the aïstopod fossil, Lethiscus stocki (Ruta et al., 2003); (7) minimum age for the divergence of the South American Pipa and the African Xenopus of 110 Mya, corresponding to the final separation of South America from Africa (Sanmartin and Ronquist, 2004).

\section{Results}

The concatenated alignment with a total of $4143 \mathrm{bp}$ consisted of rag-1, rag-2, BDNF, tyrosinase and CO1 with 1380, $819,720,651$, and 573 bp, respectively. Rag- 1 showed 773 variable and 637 parsimony-informative sites, whereas rag-2 had 
593 variable and 516 parsimony-informative positions. $B D N F$ appeared to have a relatively slow mutation rate, with only 221 variable and 114 parsimony-informative sites. Tyrosinase had 399 variable sites of which 333 were parsimony-informative. The mitochondrial COI alignment had 267 variable sites and 241 were parsimony-informative positions.

No well supported incongruencies among the results of the separate gene analyses and the combined analysis were found. The ML phylogeny based on the complete dataset (Fig. 1), rooted with Protopterus, Homo, Gallus, Alytes and the pipids (removed from Fig. 1 for better graphical representation) shows a highly supported clade composed of the Hylidae as represented by Agalychnis and Litoria sister to the Ranoidea clade. Resolution at the base of the Ranoidea clade is low, but the three major clades within the Ranoidea (see Van der Meijden et al., 2005) are highly supported. Leptopelis is placed as sister to the astylosternid Trichobatrachus and separated from the hyperoliid Hyperolius. Sister to the clade formed by the arthroleptids, astylosternids and hyperoliids, the brevicipitids form a clade as sister group to Hemisus (Hemisotidae), providing further evidence that they are not part of the Microhylidae as shown earlier using only rag-1 (Van der Meijden et al., 2004) and using both mitochondrial and nuclear sequences as well as morphological data by Frost et al. (2006).

Within the Microhylidae, basal resolution is low, but there are several well resolved clades. All phylogenetic hypotheses from the separate and combined analyses resolve the cophylines as a clade irrespective of the phylogenetic analyses used. Another highly resolved clade contains the included representatives of the South American Gastrophryninae, which was also supported as a clade in the separate analyses of all nuclear genes except those based on the tyrosinase gene alone. Notable in this clade is the highly nested position of the North American taxa Hypopachus and Gastrophryne. The Asian microhylines included form a separate clade. The Malagasy dyscophines are placed as sister to this Asian microhyline clade with low support, but this placement was consistent in all single gene analyses. Asterophrys and Cophixalus, represent the mainly New Guinean subfamily Asterophryinae are sister groups with high support. The scaphiophrynines Scaphiophryne and Paradoxophyla were resolved as sister taxa, forming a clade sister to the also Malagasy cophylines. Although this placement has only moderate support (83\% ML bootstrap support, bayesian posterior probability 1.00 ), it was supported as well by the separate analyses of both rag- 1 and rag-2. The Asian genus Calluella is placed nested among the Microhylinae, and not with the Malagasy Dyscophinae. The positions of both Otophryne and Hoplophryne are basal within the Microhylidae. Although the placement of Hoplophryne is inconsistent between the different single gene analyses, Otophryne is placed consistently basal within the microhylid clade, and not with the remaining Gastrophryninae. The Phrynomerinae are also placed basally in the Microhylidae clade.

The molecular data from Frost et al. (2006) consisted of a total of 4015 basepairs after deletion of hypervariable parts of the rRNA genes. The $28 S$ rRNA gene alignment consisted of 685 basepairs with 29 species represented. The histone $H 3$ sequence consisted of 328 basepairs, with 31 species represented. The rhodopsin alignment was 316 basepairs long, with only 14 species represented. The SIA alignment was 397 basepairs long with 29 species represented. The tyrosinase alignment, with a length of 532 basepairs, had 22 species represented. The mitochondrial section spanning $12 \mathrm{~S}$, the $\mathrm{Val}$ $t R N A$ and $16 S$ was 1786 basepairs in length and lacked only a complete sequence for Scaphiophryne, while some sequences were truncated.

Between the ML and MP phylogenies based on the molecular data from Frost et al. (2006), no well supported incongruencies were found. The genus Ramanella, represented by only a $16 S$ sequence (which came from the same individual specimen as our sequences; Table 1), was excluded from the clade representing the Microhylidae in the ML tree (Fig. 2), whereas it was included as a basal microhylid taxon in the MP tree. The clade consisting of the three included taxa of the Brevicipitidae is highly supported. The clade representing all Microhylidae receives low bootstrap support in the ML analysis (30\%) and moderate support in the MP analysis (71\%, excluding Ramanella). Basal resolution within the microhylid clade is low, but several clades equivalent to those resolved using the dataset generated for this study are resolved with low support. Asterophryines were united in a single clade with low ML (9\%) and moderate MP support $(85 \%)$. The Cophylinae clade received moderate bootstrap support (ML 60\%, MP 83\%), and is resolved as sister to Scaphiophryne with low to moderate support (ML 32\%, MP $72 \%$ ). The Microhylinae form a clade with Dyscophus as its sister taxon, although support for this placement is vanishingly low. The Microhylines Kalophrynus and Micryletta were placed outside of the main Microhyline clade. Similar to the Microhylinae, the gastrophrynines form a poorly supported clade, with high support values only for the nodes uniting highly nested taxa such as the two representatives of the genus Gastrophryne, and Nelsonophryne and Ctenophryne. The gastrophrynine Synapturanus was placed outside the main Gastrophryninae clade, in low association with the Asterophryninae. Both Hoplophryne and Phrynomantis were placed basally in the microhylid clade.

\subsection{Divergence time estimates}

The estimated divergence times of the major groups included were based on the rag-1, rag-2, and BDNF datasets only (2919 characters). The results are shown in Table 2.

\section{Discussion}

\subsection{Novel phylogenetic relationships among the Microhylidae}

In addition to the comprehensive systematic studies of the Microhylidae of Parker (1934), Van Bocxlaer et al. (2006) and Frost et al. (2006) (but also see an unpublished 


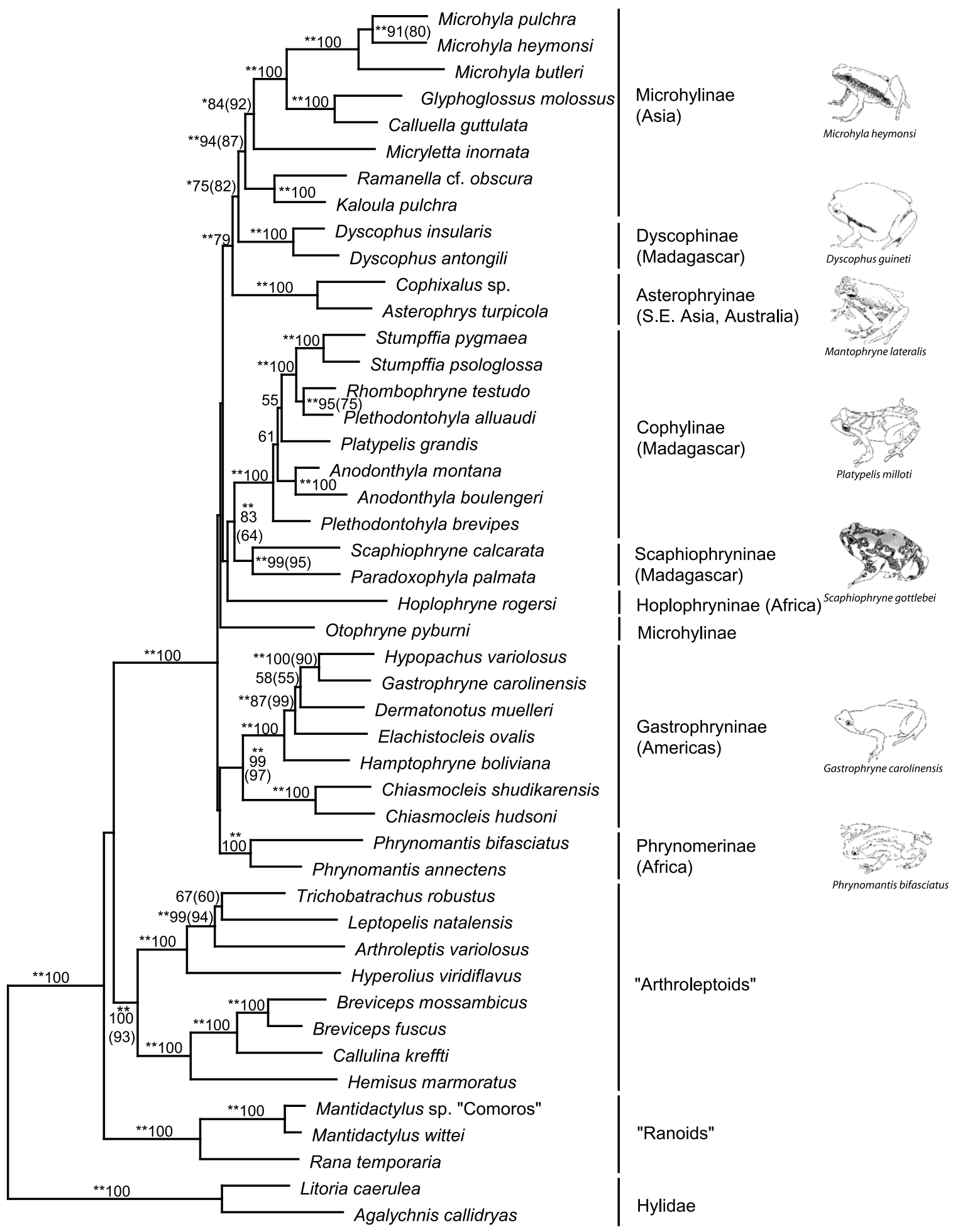

Fig. 1. ML tree, hierarchical outgroups omitted. Values are ML bootstrap support percentages of 500 replicates. Values under $50 \%$ not shown. MP bootstrap support percentages of 500 replicates given in parentheses where less than $100 \%$. A single asterisk indicates a bayesian posterior probability of over 0.95 , two asterisks indicate a bayesian posterior probability of 1.00 . Drawings show representative species of major clades.

Ph.D. thesis by S.-H. Wu from the University of Michigan, 1994), our study provides strong support for a number of clades within this family. Many of these agree with those resolved in previous studies, but several novel phylogenetic relationships were discovered.
One of the more surprising results is the moderately supported placement of the Scaphiophryninae as sister to the Cophylinae. Such a sister group relationship of these two endemic Malagasy subfamilies has, to our knowledge, hitherto not been proposed. The placement of the Scaphiophryninae 
Table 2

Divergence time estimates (Age), 95\% Confidence interval (CI), and corresponding standard deviation (SD)

\begin{tabular}{|c|c|c|}
\hline Clade & Age (Mya) \pm SD (My) & $95 \% \mathrm{CI}(\mathrm{My})$ \\
\hline Lissamphibia-Amniota (min. 338 Mya) & $356 \pm 46$ & $281-446$ \\
\hline Anura-Caudata (min. 230 Mya) & $326 \pm 40$ & $255-412$ \\
\hline Diapsids_-Synapsids (338-288 Mya) & $305 \pm 41$ & 232-392 \\
\hline Ranoidea-Hyloidea & $151 \pm 32$ & $116-197$ \\
\hline Xenopus-Pipa (min. 110 Mya) & $142 \pm 23$ & $102-193$ \\
\hline Ranoidea & $119 \pm 17$ & $89-157$ \\
\hline Hyperolius-(Arthroleptis-(Trichobatrachus-Leptopelis)) & $77 \pm 13$ & $55-106$ \\
\hline Brevicipitidae-Hemisus & $75 \pm 13$ & $53-104$ \\
\hline Mantellidae_Ranidae & $61 \pm 11$ & $43-84$ \\
\hline Litoria-Agalychnis (min. $42 \mathrm{Mya)}$ & $53 \pm 9$ & $42-75$ \\
\hline Mantidactylus wittei-M. sp. "Comoros" (max. 15 Mya) & $11 \pm \mathbf{2}$ & $6.7-15$ \\
\hline Alytes muletensis-A. dickhilleni (min. $5 \mathrm{Mya})$ & $\mathbf{1 0} \pm \mathbf{5}$ & $2.3-23$ \\
\hline Scaphiophryninae - Cophylinae & $53 \pm 9$ & $38-74$ \\
\hline Gastrophryninae & $53 \pm 10$ & $37-74$ \\
\hline Microhylinae & $52 \pm 9$ & $37-72$ \\
\hline Phrynomerinae & $47 \pm 9$ & $32-66$ \\
\hline Scaphiophryninae & $45 \pm 8$ & $31-64$ \\
\hline Cophylinae & $32 \pm 7$ & $22-47$ \\
\hline Cophixalus-Asterophrys & $20 \pm 5$ & $12-30$ \\
\hline Dyscophinae & $19 \pm 5$ & $11-29$ \\
\hline Hypopachus-Gastrophryne & $17 \pm 4$ & $10-27$ \\
\hline
\end{tabular}

Ages of higher taxa are the divergence times of the most basal branches in that clade, based on the taxa included in this study.

Constraints imposed by calibration points are given in the first column, and the posterior age estimates recovered for these nodes are indicated in bold face.

as sister to the Cophylinae is rather well supported by our data and biogeographically more parsimonious, and the relationships among these taxa therefore demand closer scrutiny. The study of Frost et al. (2006) however, placed the Scaphiophryne basal to the Asian Microhylines, far removed from the Cophylinae. Our reanalyses of these data excluding morphological characters concur with the placement of the Scaphiophryninae with the cophylines (Fig. 2), be it with a low bootstrap support value of $32 \%$ (MP $72 \%$ ). The often proposed position of the Scaphiophryninae as sister to the remaining Microhylidae (Scoptanura) (Wassersug, 1984; Duellman and Trueb, 1986; Wassersug, 1989; Ford and Cannatella, 1993; Haas, 2003) cannot be unambiguously ruled out by our data.

Based on the great differences between the tadpole of Scaphiophryne, which possess a horny beak and oral denticles and resembles a ranoid tadpole, and Paradoxophyla, which lacks all keratinized oral structures and which is a typical microhylid tadpole, it was suggested that the scaphiophrynines might not be monophyletic (Ford and Cannatella, 1993). Haas (2003) suggested based on larval characters that Paradoxophyla is more closely related to the Phrynomerinae. Our molecular data provide strong evidence for a sister-group relationship of Paradoxophyla and Scaphiophryne. Parsimony arguments therefore suggest that the morphology of the Scaphiophryne tadpole, inter- mediate between a ranoid and microhylid larval morphology, should be interpreted to be a reversal from the microhylid type. The alternative, considering the Scaphiophryne tadpole as the ancestral form for microhylids, would instead imply the unlikely hypothesis that Scaphiophryne has evolved its filter-feeding tadpole morphology fully in parallel to other microhylids.

The isolated position of Otophryne corroborates the suggestion of Wassersug and Pyburn (1987) that this species is not a microhyline. They suggested its unique characters might merit the erection of a new subfamily. The phylogenetic hypothesis by Wild (1995), based on the combined morphological data from Zweifel (1986) and Donnelly et al. (1990), instead indicated that Otophryne is nested in the American Gastrophryninae. Our molecular data resolve Otophryne as a distinct taxon in the microhylid clade, not closely associated with any other microhylid subclade, based both on the combined as well as the single gene analyses. Although basal resolution in the current phylogeny is too low to interpret the position of Otophryne as being basal, the possibility of such a placement allows us to consider some of the unique morphological traits of the psammonic larva, especially the keratinized mouthparts, as a possible plesiomorphic character rather than an adaptation related to its burrowing lifestyle. Excluding Otophryne, the remaining Gastrophryninae form one of the most distinct 


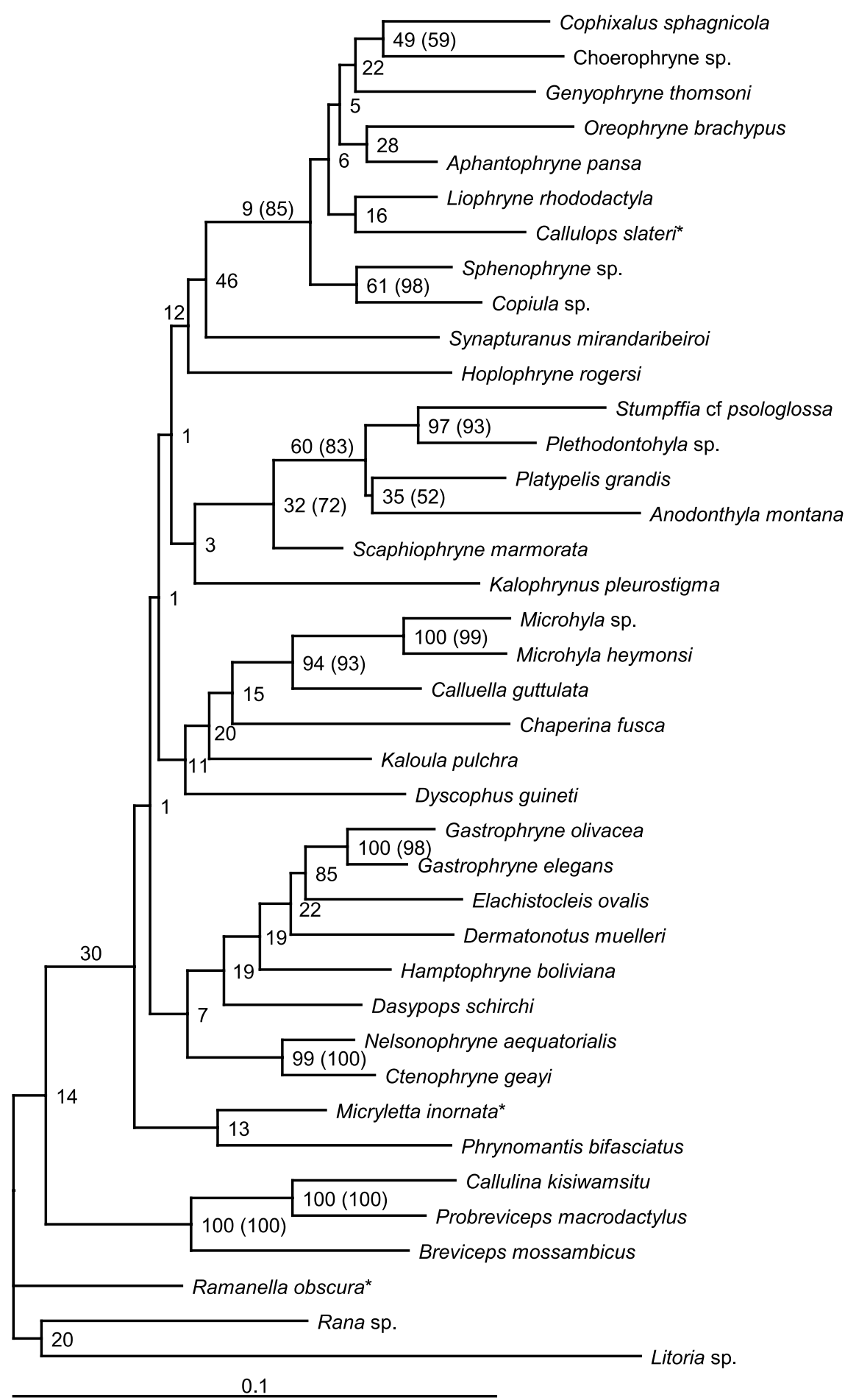

Fig. 2. ML tree of reanalyzed molecular data from Frost et al. (2006). Values are ML (MP) bootstrap support percentages of 300 replicates and 500 replicates, respectively. MP bootstrap values lower than 50\% not shown. Taxa for which only $12 \mathrm{~S}$ or $16 \mathrm{~S}$ sequences are available are marked with an asterisk.

and well supported groups within the microhylid clade, clearly unrelated to the Asian Microhylinae. This is congruent with the findings of Haas (2003) using larval morphological characters, and those of Frost et al. (2006) based on both morphological and molecular data. Resolution within this group is high and the two North American taxa, Hypopachus and Gastrophryne, are firmly nested within the remaining South American clade.
The Microhylinae are here resolved as a highly supported clade. Basal to this clade are the Malagasy dyscophines and the representatives of the mainly New Guinean subfamily Asterophryinae (Asterophrys and Cophixalus).

The topology resulting from our reanalysis of the molecular data from Frost et al. (2006) differed markedly from that presented in the Frost et al. (2006) paper in a 
number of points. Their placement of Kalophrynus as the sister taxon to the remaining Microhylidae was not recovered by our reanalysis which rather placed this taxon at an unresolved basal position within the Microhylidae. Also the position of Synapturanus basal to all microhylids save Kalophrynus was not supported by our reanalysis. However, the exclusion of Synapturanus from the Gastrophryninae clade is corroborated, placing this South American species basal in the Microhylidae clade outside of the Gastrophryninae, similar to Otophryne. The possible basal position places more emphasis of the enigmatic character of these two taxa. Our reanalysis also differed in the placement of the Malagasy taxa Scaphiophryne and Dyscophus. The former was resolved by Frost et al. (2006) as the sister taxon to the Microhylinae, whereas our reanalysis found this taxon to be the sister taxon of the cophylines, a placement in agreement with our own data. Dyscophus was placed sister to the Asterophryinae in the study of Frost et al. (2006), whereas our data placed this taxon sister to the Microhylinae, similar to the findings of Van Bocxlaer et al. (2006). Our reanalysis of the molecular data from Frost et al. (2006) corroborated the placement of Dyscophus with the Microhylinae, be it with little support for this placement. The similarity of the phylogeny based on the molecular data of Frost et al. (2006) and that based on our own data transfers high credibility to our topology. The alternative topology recovered by Frost et al. (2006) can probably be attributed to the different methods of alignment and analysis used by these authors (optimization parsimony) but may also be due to the inclusion of morphological characters and hypervariable regions of the rRNA genes in their dataset. Further work will be required to resolve this point.

Despite the inclusion of over $4 \mathrm{kbp}$ of sequence data in our analysis, the basal relationships among the well resolved microhylid clades remain somewhat unresolved. The inclusion of more sequence data, and a more comprehensive taxon sampling might improve the resolution in this part of the tree. Lack of resolution among the basal nodes of the Microhylidae was also evident in the study of Frost et al. (2006) and Van Bocxlaer et al. (2006). The contrast between the lack of resolution basally within the Microhylidae with the otherwise well resolved clades in three separate studies could point to a "biological" polytomy, due to a fast initial radiation. This pattern is similar to that found basally in the Ranoidae (Bossuyt et al., 2006; Van der Meijden et al., 2005), and similarly complicates the selection among alternative biogeographic scenarios.

\subsection{Relationships among "Arthroleptoids"}

The position of Leptopelis as sister to the arthroleptid Trichobatrachus, corroborates the findings of Emerson et al. (2000), that Leptopelis is distinct from the hyperoliids, and those of Vences et al. (2003a) and Frost et al. (2006), that the leptopelines are closely related to the astyloster- nids. Our study supplies additional evidence of the close relation of Hemisus to the brevicipitids, which has previously been shown by Frost et al. (2006). This relationship had previously been hypothesized by Blommers-Schlosser (1993) based on morphological arguments, but Channing (1995) showed that only a single morphological synapomorphy (a single median thyroid gland) supported the sister relationship between the Brevicipitinae and Hemisus.

\subsection{Alternate biogeographic scenarios for the Microhylidae}

Divergence time estimates place the initial divergence within the Microhylidae at $66 \mathrm{Mya}$ (with a $95 \%$ confidence interval of 47-90 Mya), but the last common ancestor of the Microhylidae and their closest ranoid relatives at $116 \mathrm{Mya}$ (87-153 Mya). This dating largely agrees with the recent analysis of Bossuyt et al. (2006) who found an initial split within microhylids immediately after the Cretaceous-Paleocene boundary, and with Van Bocxlaer et al. (2006) who recovered a divergence time of about $88 \mathrm{Mya}$ for the initial microhylid divergence and 127 Mya for their split from their nearest relatives. The early microhylids found themselves thus on Gondwana, around or after the disconnection of Madagascar and India from the mainland 121 Mya (Sanmartin and Ronquist, 2004). Several scenarios have been proposed to explain their current distribution.

\subsubsection{Ancient vicariance}

Savage (1973) proposed a scenario based almost entirely on vicariance due to the fragmentation of Gondwana. Savage suggested that vicariance events led to the presence of microhylids in South America, Africa, Madagascar, India, and Australia. The origins of the Microhylinae in Asia have been proposed to be due to their presence in Madagascar-India (Duellman and Trueb, 1986), where they originated after an ancient vicariant split from Africa. After the separation of Madagascar and India by the Mascarene basin, 88-84 Mya, India would have acted as "biotic ferry" and transported several ranoid frogs (Natatanura sensu Frost et al., 2006) as well as microhylids to Asia, where they underwent extensive radiations (Duellman and Trueb, 1986; Bossuyt and Milinkovitch, 2001). These frog lineages previously would have been present on the Madagascar-India continent since its disconnection from Africa. Madagascar and India, however, had broken off from Africa (121 Mya) before the initial divergence of microhylids at 66 Mya (47$90 \mathrm{Mya})$. Assuming that our age estimates are correct, the initial splits among microhylids would therefore be distinctly younger than this continental separation, making it unlikely that the presence on Madagascar of cophylines and scaphiophrynines, which originated 53 Mya (38$74 \mathrm{Mya}$ ), is due to vicariance.

The basal position of both the African taxa Hoplophryne and Phrynomantis, and the South American taxa Otophryne and Synapturanus suggest a possible vicariant split between African and South American taxa. Africa 
and South America had separated at 110 Mya, before the initial radiation of the extant Microhylidae, and therefore vicariance is unlikely in light of this divergence time estimate. South America remained indirectly connected to Australia and New Guinea, but not to Africa, through Antarctica until $35 \mathrm{Mya}$. A hypothesis of ancestors from South America colonizing Asia via Antarctica and Australia is in accordance with the basal position of the Asterophryinae and Genyophryninae to the Microhylinae, and the divergence between asterophryines from microhylines at 57 Mya (40-79 Mya). The initial divergence between the Australo-New Guinean taxa is estimated at 20 Mya, but only two possibly closely related taxa (Sumida et al., 2000) are included in our study. The fossil asterophryine Australobatrachus, from the Oligocene to Miocene of Australia provides further evidence for this possibility. Counter to this scenario is the low species diversity presently found in Australia compared to that on New Guinea.

\subsubsection{Recent dispersal}

Feller and Hedges (1998) proposed that the origin of the Microhylidae lies in Africa, and subsequent dispersal to Asia, and from there to South America via North America led to the current distribution. Although appealing, this scenario is at odds with our phylogenetic reconstructions and divergence time estimates. The dispersal of the Microhylidae to Asia after the reconnection of Africa to Eurasia through the Arabian Peninsula, latest 10 Mya (McQuarrie et al., 2003) as proposed by Feller and Hedges, is in disagreement with our divergence time estimates. The initial radiation of the Asian Microhylinae is estimated at $52 \mathrm{Mya}$ (37-72 Mya), well before the reconnection of Africa to Eurasia. Our data also show the North American microhylines to be nested within the South American clade. This contradicts the hypothesis of the colonization of South America from North America, unless one postulates extinction and recolonization for North America. On the contrary, North America was probably colonized by dispersal from South America. Feller and Hedges (1998) propose, for hyloid frogs, a dispersal route to North America across the proto-Antilles in the late Cretaceous. It is unlikely that the microhylids also used this route because the split between North and South American taxa is younger: divergence time estimates place the most recent common ancestor of the North American taxa Hypopachus and Gastrophryne at $17 \mathrm{Mya}$ (10-27 Mya), closer to the connection of North and South America through the Panama isthmus approximately 5-3.5 Mya. The North American microhyline taxa might therefore have dispersed from South America across the Panama isthmus or across the sea prior to the great faunal interchange. Since the monophyly of the North American taxa is well corroborated and was also found by Frost et al. (2006), to explain the colonization of North America along with the great faunal interchange would require to assume the extinction of the putative closest relatives of Gastrophryne, and of the ones of Hypopachus, in southern America.

\subsubsection{Ancient dispersal}

As summarized above, the original "biotic ferry" hypothesis strictly implied vicariance to explain the distribution of microhylids and natatanurans in Africa, Madagascar and India/Asia, but the molecular age estimates indicate that microhylids and natatanurans are younger than the generally accepted age of geological separation among these land masses. Van Bocxlaer et al. (2006) alternatively proposed that land connections among Gondwanan landmasses may have persisted longer, contrary to the traditional paleogeographical reconstructions. In fact, the Kerguelen plateau provided a connection between Madagascar-India and Antarctica (and thereby with Australia and South America) in the Late Cretaceous which led to faunal interchanges (Krause et al., 1999; Noonan and Chippindale, 2006), and the drifting Indian continent may have been simultaneously close to Madagascar, Africa, and Asia (Patriat and Segoufin, 1988; Briggs, 2003). The hypothesis of Van Bocxlaer et al. (2006) largely relies on a phylogenetic reconstruction of microhylids, based on a dataset of 2865 nucleotides, which similar to our tree has almost no support for basal relationships among major clades. It therefore is too early to fully evaluate this scenario that places two African taxa (Phrynomantis and Hoplophryne) as most basal microhylids. However, it is obvious that the hypothesis of Van Bocxlaer et al. (2006), in contradiction to the title of their paper, is strongly dispersal-oriented. There is no doubt that Gondwana was highly fragmented already in the Early Cretaceous, and according to the available divergence time estimates microhylids and natatanurans had not yet diverged at this time. An initial widespread Gondwanan distribution of these frogs can therefore not be invoked, and they must instead have originated on one of the Gondwana fragments. At least for the Natatanura this was most likely Africa since the basal lineages of ranoids and natatanurans are endemic to that continent (Van der Meijden et al., 2005). After a presumed secondary contact between India and Africa (Briggs, 2003), a subset of these frogs could have dispersed to India, radiated there, and several subgroups then again dispersed to Madagascar (and possibly from there, once more, over the Kerguelen plateau and Antarctica to South America). Hence, the initial phylogenetic splits explaining the current transcontinental distribution of these frogs would have been two or more dispersals (over land or crossing narrow sea straits). Only subsequently would the connections between AfricaIndia and India-Madagascar have been severed (causing definitive isolation that could be interpreted as vicariance), and the "biotic ferry" India completed its journey towards Asia. In fact, Van Bocxlaer et al. (2006) themselves use the term "mass coherent dispersal" to explain the encountered patterns. This variant of the scenario is even more appealing because it easily explains, without assuming multiple extinctions, why the Malagasy taxa (especially the natatanuran family Mantellidae) are deeply nested within the Indo-Asian taxa. 
Again assuming accretions of landmasses, a further alternative not mentioned by Van Bocxlaer et al. (2006) and equally explaining the initial splits in microhylids and natatanurans, would be a trans-Tethyan connection leading to a colonization of Eurasia via Africa, and subsequently a dispersal route via India to Madagascar, and then via Antarctica to Australia and South America. We do not favor this scenario which is unlikely despite previous suggestions of Cretaceous-Paleocene connections across the Tethys (e.g., Gheerbrant, 1990). It exemplifies, however, that a plethora of alternative explanations for the current distribution patterns are available, and that the biotic data so far do not unequivocally contradict any particular aspect of the prevalent geological reconstructions.

\subsubsection{Biogeographic conclusions}

From the discussions above it becomes clear that a more comprehensive taxon sampling as well as a better phylogenetic resolution will be necessary to unambiguously resolve the biogeographic history of the Microhylidae. The inclusion of more New Guinean asterophrynines, as well as inclusion of Australian taxa might possibly resolve the order of colonization of these two areas. Increased taxon sampling, as well as a larger dataset might better resolve the relationships between the Microhylinae, the Dyscophinae and the Asterophryninae and thus help understanding the direction of colonization in this case. Considering the very low support for the basal relationships among microhylids, and the short time interval in which it occurred (66$53 \mathrm{Mya}$ ), it seems likely that these frogs arose by a radiation which may have been too fast to be fully reconstructed. Some overseas dispersal probably occurred (e.g., from southern to northern America) as well as some dispersal across landmasses and subsequent vicariance. Eventually, it is not unlikely that the biogeographic history of this and other frog families will turn out to be highly complex, shaped by a mixture of vicariance and dispersal events rendering unidimensional hypotheses as too simplistic and optimistic.

\section{Acknowledgments}

We thank Jens V. Vindum at the California Academy of Sciences, San Francisco, Steve Richards at the James Cook University, Frank Glaw at the Zoologische Staatssammlung München, Alexander Kupfer at the Natural History Museum, London, and Carla Cicero at the Museum for Vertebrate Zoology, Berkeley (Loan No. 6205), for generously providing tissue samples crucial to this work. Thanks to Dirk Steinke and Frank Glaw for valuable discussions, and to Franky Bossuyt and an anonymous reviewer for their helpful comments. We thank our fellow microhylophilic colleagues with whom we have enjoyed constructive correspondence under the auspice of AmphibiaTree. This work was funded by the Deutsche Forschungsgemeinschaft (Grant ME1725/10-1).

\section{References}

Amphibiaweb, Information on amphibian biology and conservation. [web application]. 2006. Berkeley, California: AmphibiaWeb. Available: http://amphibiaweb.org/.

Andreone, F., Vences, M., Vieites, D.R., Glaw, F., Meyer, A., 2005. Recurrent ecological adaptations revealed through a molecular analysis of the secretive cophyline frogs of Madagascar. Mol. Phylogenet. Evol. 34, 315-322.

Barnes, W.M., 1994. PCR amplification of up to $35 \mathrm{~kb}$ DNA with high fidelity and high yield from lambda bacteriophage templates. Proc. Natl. Acad. Sci. USA 91, 2216-2220.

Biju, S.D., Bossuyt, F., 2003. New frog family from India reveals an ancient biogeographical link with the Seychelles. Nature 425, 711-713.

Blommers-Schlosser, R.M.A., 1993. Systematic relationships of the Mantellinae Laurent 1946 (Anura Ranoidea). Ethol. Ecol. Evol. 2, 199-218.

Bossuyt, F., Milinkovitch, M.C., 2000. Convergent adaptive radiations in Madagascan and Asian ranid frogs reveal covariation between larval and adult traits. Proc. Natl. Acad. Sci. USA 97, 6585-6590.

Bossuyt, F., Milinkovitch, M.C., 2001. Amphibians as indicators of early tertiary "Out-of-India" dispersal of vertebrates. Science 292, 93-95.

Bossuyt, F., Brown, R.M., Hillis, D.M., Cannatella, D.C., Milinkovitch, M.C., 2006. Phylogeny and biogeography of a cosmopolitan frog radiation: Late Cretaceous diversification resulted in continent-scale endemism in the family Ranidae. Syst. Biol. 55, 579-594.

Briggs, J.C., 2003. The biogeographic and tectonic history of India. J. Biogeogr. 30, 338-381.

Bruford, M.W., Hanotte, O., Brookfield, J.F.Y., Burke, T., 1992. Singlelocus and multilocus DNA fingerprinting. In: Hoezel, A.R. (Ed.), The South American Herpetofauna: Its Origin, Evolution, and Dispersal. Molecular Genetic Analysis in Conservation. IRL Press, Oxford.

Channing, A., 1995. The relationship between Breviceps (Anura: Microhylidae) and Hemisus (Hemisotidae) remains equivocal. J. Herpet. Ass. Afr. 44, 55-57.

Darst, C.R., Cannatella, D.C., 2004. Novel relationships among hyloid frogs inferred from $12 \mathrm{~S}$ and $16 \mathrm{~S}$ mitochondrial DNA sequences. Mol. Phylogenet. Evol. 31, 462-475.

Donnelly, M.A., De Sá, R.O., Guyer, C., 1990. Description of the tadpoles of Gastrophryne pictiventris and Nelsonophryne aterrima (Anura: Microhylidae), with a review of morphological variation in free-swimming microhylid larvae. Am. Mus. Novit. 2976, 1-19.

Dubois, A., 1992. Notes sur la classification des Ranidae (amphibiens anoures). Bull. Mens. Soc. Linn. Lyon 61, 305-352.

Dubois, A., 2005. Amphibia Mundi. 1.1.; An ergotaxonomy of recent amphibians. Alytes 23, 1-24.

Duellman, W.E., 1979. The South American Herpetofauna: Its Origin, Evolution, and Dispersal. Museum of Natural History. The University of Kansas, Lawrence, Kansas.

Duellman, W.E., Trueb, L., 1986. Biology of Amphibians. McGraw Hilll, New York.

Emerson, S.B., Richards, C., Drewes, R.C., Kjer, K.M., 2000. On the relationships among ranoid frogs: A review of the evidence. Herpetologica $56,209-230$

Farris, J.S., Källersjö, M., Kluge, A.G., Bult, C., 1994. Testing significance of incongruence. Cladistics 10, 315-319.

Feller, A.E., Hedges, S.B., 1998. Molecular evidence for the early history of living amphibians. Mol. Phylogenet. Evol. 9, 509-516.

Felsenstein, J., 1984. Distance methods for inferring phylogenies: A justification. Evolution 38, 16-24.

Ford, L.S., Cannatella, D.C., 1993. The major clades of frogs. Herpetol. Monogr. 7, 94-117.

Fromhage, L., Vences, M., Veith, M., 2004. Testing alternative vicariance scenarios in Western Mediterranean discoglossid frogs. Mol. Phylogenet. Evol. 31, 308-322. 
Frost, D.R., Grant, T., Faivovich, J., Baina, R.H., Haas, A., Haddad, C.F.B., Sá, R.O.D., Channing, A., Wilkinson, M., Donnellan, S.C., Raxworthy, C.J., Campbell, J.A., Blotto, B.L., Moler, P., Drewes, R.C., Nussbaum, R.A., Lynch, J.D., Green, D.M., Wheeler, W.C., 2006. The amphibian tree of life. Bull. Amer. Mus. Nat. Hist. 297, $1-$ 291.

Gheerbrant, E., 1990. On the early biogeographical history of the African placentals. Historical Biol. 4, 107-116.

Graur, D., Martin, W., 2004. Reading the entrails of chickens: Molecular timescales of evolution and the illusion of precision. Trends Genet. 20, $80-86$

Guindon, S., Gascuel, O., 2003. A simple, fast, and accurate algorithm to estimate large phylogenies by maximum likelihood. Syst. Biol. 52, 696 704.

Haas, A., 2003. Phylogeny of frogs as inferred from primarily larval characters (Amphibia: Anura). Cladistics 19, 23-89.

Hanken, J., Wake, D.B., 1993. Miniaturization of body size: Organismal consequences and evolutionary significance. Annu. Rev. Ecol. Syst. 24, 501-519.

Hebert, P., Cywinska, A., Ball, S., Dewaard, J., 2003. Biological identification through DNA barcodes. Proc. R. Soc. B. 270, 313-321.

Hebert, P., Stoeckle, M., Zemlak, T., Francis, C., 2004. Identification of birds through COI DNA barcodes. PLoS Biol. 2, e312.

Hedges, S.B., Hass, C.A., Maxson, L.R., 1992. Caribbean biogeography: Molecular evidence for dispersal in West Indian terrestrial vertebrates. Proc. Natl. Acad. Sci. USA 89, 1909-1913.

Hoegg, S., Vences, M., Brinkmann, H., Meyer, A., 2004. Phylogeny and comparative substitution rates of frogs inferred from sequences of three nuclear genes. Mol. Biol. Evol. 21, 1188-1200.

Hoskin, C.J., 2004. Australian microhylid frogs (Cophixalus and Austrochaperina): Phylogeny, taxonomy, calls, distributions and breeding biology. Aust. J. Zool. 52, 237-269.

Huelsenbeck, J.P., Ronquist, F., 2001. MRBAYES: Bayesian inference of phylogenetic trees. Bioinformatics 17, 754-755.

Köhler, J., Vieites, D.R., Bonett, R.M., Garcı'a, F.H., Glaw, F., Steinke, D., Vences, M., 2005. New amphibians and global conservation: A boost in species discoveries in a highly endangered vertebrate group. BioScience $55,693-696$

Krause, D.W., Rogers, R.R., Forster, C.A., Hartman, J.H., Buckley, G.A., Sampson, S.D., 1999. The late cretaceous vertebrate fauna of Madagascar: Implications for Gondwanan paleobiogeography. GSA Today (Publ. Geol. Soc. Am.) 9, 1-7.

Kumar, S., Tamura, K., Nei, M., 2004. MEGA3: Integrated software for molecular evolutionary genetics analysis and sequence alignment. Brief Bioinform. 5, 150-163.

Loader, S.P., Gower, D.J., Howell, K.M.N.D., Rödel, M.-O., Clarke, B.T., De Sá, R., Cohen, B.L., Wilkinson, M., 2004. Phylogenetic relationships of African microhylid frogs inferred from DNA sequences of mitochondrial $12 \mathrm{~S}$ and $16 \mathrm{~S}$ rRNA genes. Org. Divers Evol. 4, 227-235.

McDiarmid, R.W., Altig, R., 1999. Tadpoles: The Biology of Anuran Larvae. xvi, 444. University of Chicago Press, Chicago and London.

McQuarrie, N., Stock, J.M., Verdel, C., Wernicke, B.P., 2003. Cenozoic evolution of Neotethys and implications for the causes of plate motions. Geophys. Res. Lett. 30, 6.1-6.4.

Measey, G.J., Vences, M., Drewes, R.C., Chiari, Y., Melo, M., Bourles, B., 2007. Freshwater paths across the ocean: Molecular phylogeny of the frog Ptychadena newtoni gives insights into amphibian colonization of oceanic islands. J. Biogeogr. 34, 7-20.

Noonan, B.P., Chippindale, P.T., 2006. Vicariant origin of malagasy reptiles supports late cretaceous antarctic land bridge. Amer. Nat. 168, 730-741.

Parker, B.A., 1934. A Monograph of the Frogs of the Family Microhylidae. The British Museum, London.

Patriat, P., Segoufin, J., 1988. Reconstruction of the central indian ocean. In: Scotese, C.R., Sager, W.W. (Eds.), Mesozoic and Cenozoic Plate Reconstructions. Tectonophysics, 155, pp. 211-234.
Posada, D., Crandall, K.A., 1998. Modeltest: Testing the model of DNA substitution. Bioinformatics 14, 817-818.

Ruta, M., Coates, M.I., Quicke, D.L., 2003. Early tetrapod relationships revisited. Biol. Rev. Camb. Philos. Soc. (London) 78, 251-345.

San Mauro, D., Vences, M., Alcobendas, M., Zardoya, R., Meyer, A., 2005. Initial diversification of living amphibians predated the breakup of Pangaea. Am. Nat. 165, 590-599.

Sanchiz, B., 1998. Encyclopedia of Palaeoherpetology Part 4. Salienta, Pfeil, München.

Sanmartin, I., Ronquist, F., 2004. Southern hemisphere biogeography inferred by event-based models: Plant versus animal patterns. Syst. Biol. 2, 216-243

Savage, J.M., 1973. The geographic distribution of frogs: Patterns and predictions. In: Vial, J.L. (Ed.), Evolutionary Biology of Anurans: Contemporary Research on Major Problems. University of Missouri Press, Colombia, Missouri.

Scott, E., 2005. A phylogeny of ranid frogs (Anura: Ranoidea: Ranidae), based on a simultaneous analysis of morphological and molecular data. Cladistics 21, 507-574.

Seddon, J.M., Baverstock, P.R., Georges, A., 1998. The rate of mitochondrial $12 \mathrm{~S}$ rRNA gene evolution is similar in freshwater turtles and marsupials. J. Mol. Evol. 4, 460-464.

Sumida, M., Allison, A., Nishioka, M., 2000. Evolutionary relationships among 12 species belonging to three genera of the family Microhylidae in Papua New Guinea revealed by allozyme analysis. Biochem. Syst. Ecol. 8, 721-736.

Swofford, D.L., 2002. PAUP*. Phylogenetic analysis using parsimony (* and other methods). Sinauer Associates, Sunderland, MA.

Thompson, J.D., Higgins, D.G., Gibson, T.J., 1994. Clustal W: Improving the sensitivity of the progressive multiple sequence alignment through sequence weighting, positions-specific gap penalties and weight matrix choice. Nucleic Acids Res. 22, 4673-4680.

Thorne, J.L., Kishino, H., 2002. Divergence time and evolutionary rate estimation with multilocus data. Syst. Biol. 5, 689-702.

Van Bocxlaer, I., Roelants, K., Biju, S.D., Nagaraju, J., Bossuyt, F., 2006. Late Cretaceous Vicariance in Gondwanan Amphibians. PLoS ONE 1, e74.

Van der Meijden, A., Vences, M., Meyer, A., 2004. Novel phylogenetic relationships of the enigmatic brevicipitine and scaphiophrynine toads as revealed by sequences from the nuclear Rag-1 gene. Proc. R. Soc. B 271, S378-S381.

Van der Meijden, A., Vences, M., Hoegg, S.I., Meyer, A., 2005. A previously unrecognized radiation of ranid frogs in Southern Africa revealed by nuclear and mitochondrial DNA sequences. Mol. Phylogenet. Evol. 37, 674-685.

Vences, M., Kosuch, J., Glaw, F., Böhme, W., Veith, M., 2003a. Molecular phylogeny of hyperoliid treefrogs: Biogeographic origin of Malagasy and Seychellean taxa and re-analysis of familial paraphyly. J. Zool. Syst. Evol. Res. 41, 205-215.

Vences, M., Vieites, D.R., Glaw, F., Brinkmann, H., Kosuch, J., Veith, M., Meyer, A., 2003b. Multiple overseas dispersal in amphibians. Proc. R. Soc. B. 1532, 2435-2442.

Vences, M., Thomas, M., Van der Meijden, A., Chiari, Y., Vieites, D.R., 2005. Comparative performance of the 16S rRNA gene in DNA barcoding of amphibians. Front Zool. 2, 5 .

Wassersug, R., 1984. The Pseudohemisus tadpole: A morphological link between microhylid (Orton type 2) and ranoid (Orton type 4) larvae. Herpetologica 40, 138-149.

Wassersug, R., 1989. What, if anything is a microhylid (Orton type II) tadpole? In: Splechtna, H. (Ed.), Trends in Vertebrate Morphology. G. Fischer, Stuttgart, New York.

Wassersug, R.J., Pyburn, W.F., 1987. The biology of the Pe-ret' toad, Otophryne robusta (Microhylidae), with special consideration of its fossorial larva and systematic relationships. Zool. J. Linn. Soc. 91, $137-169$. 
Wiens, J.J., Fetzner, J.W., Parkinson, C.L., Reeder, T.W., 2005. Hylid frog phylogeny and sampling strategies for speciose clades. Syst. Biol. 5, 719-748.

Wild, E.R., 1995. New genus and species of Amazonian microhylid frog with a phylogenetic analysis of New World genera. Copeia 4, 837-849.
Yang, Z., 1997. PAML: A program package for phylogenetic analysis by maximum likelihood. Computer Applications in the BioSciences 13, 555-556.

Zweifel, R.G., 1986. A new genus and species of microhylid frog from the Cerro de la Neblina region of Venezuela and a discussion of relationships among New World microhylid genera. Am. Mus. Novit. 2863, 1-24. 